\title{
Peripheral interleukin-1 $\beta$ inhibits arcuate kiss1 cells and LH pulses in female mice
}

\author{
Katherine N Makowski ${ }^{1, *}$, Michael J Kreismann ${ }^{2, *}$, Richard B McCosh ${ }^{2}$, Ali A Raad ${ }^{2}$ and Kellie M Breen ${ }^{2}$ \\ ${ }^{1}$ Animal Care Program, University of California, San Diego, La Jolla, California, USA \\ 2Department of Obstetrics, Gynecology and Reproductive Sciences, University of California, San Diego, La Jolla, California, USA
}

Correspondence should be addressed to K M Breen: kbchurch@ucsd.edu

*(K N Makowski and M J Kreisman contributed equally to this work)

\begin{abstract}
Peripheral immune/inflammatory challenges rapidly disrupt reproductive neuroendocrine function. This inhibition is considered to be centrally mediated via suppression of gonadotropin-releasing hormone secretion, yet the neural pathway(s) for this effect remains unclear. We tested the hypothesis that interleukin-1 $\beta$ inhibits pulsatile luteinizing hormone secretion in female mice via inhibition of arcuate kisspeptin cell activation, a population of neurons considered to be the gonadotropinreleasing hormone pulse generator. In the first experiment, we determined that the inhibitory effect of peripheral interleukin-1 $\beta$ on luteinizing hormone secretion was enhanced by estradiol. We next utilized serial sampling and showed that interleukin-1 $\beta$ reduced the frequency of luteinizing hormone pulses in ovariectomized female mice treated with estradiol. The interleukin-1 $\beta$-induced suppression of pulse frequency was associated with reduced kisspeptin cell activation, as determined by c-Fos coexpression, but not as a result of impaired responsiveness to kisspeptin challenge. Together, these data suggest an inhibitory action of interleukin-1 $\beta$ upstream of kisspeptin receptor activation. We next tested the hypothesis that estradiol enhances the activation of brainstem nuclei responding to interleukin-1 $\beta$. We determined that the expression of interleukin-1 receptor was elevated within the brainstem following estradiol. Interleukin$1 \beta$ induced c-Fos in the area postrema, ventrolateral medulla, and nucleus of the solitary tract; however, the response was not increased by estradiol. Collectively, these data support a neural mechanism whereby peripheral immune/inflammatory stress impairs reproductive neuroendocrine function via inhibition of kisspeptin cell activation and reduced pulsatile luteinizing hormone secretion. Furthermore, these findings implicate the influence of estradiol on peripherally mediated neural pathways such as those activated by peripheral cytokines.
\end{abstract}

\section{Introduction}

It is well accepted that stress can impair reproduction by suppressing gonadotropin secretion; yet, the various factors and neural mechanisms mediating the response to stress are still poorly defined. Acute immune or inflammatory challenges, such as injury or infection, represent a type of reactive stressor that requires rapid

\section{Key Words:}

- immune/inflammatory

- luteinizing hormone

- stress

- $\mathrm{GnRH}$ 
body-to-brain communication to mediate survival and recovery. Indeed, exposure to lipopolysaccharide (LPS), a bacterial endotoxin and commonly used model of an immune/inflammatory challenge, elicits rapid changes in neuroendocrine function, including activation of the hypothalamic-pituitary-adrenal (HPA) axis as well as suppression in pulsatile luteinizing hormone (LH) secretion (Battaglia et al. 1998).

Both the mediator(s) and neural mechanism underlying the inhibitory effect of inflammatory stress on LH secretion remains unclear. One potential mediator of neuroendocrine responses to LPS is the proinflammatory cytokine interleukin-1 $\beta$ (IL-1 $\beta$ ) (Turnbull \& Rivier 1999). Evidence that antagonism of interleukin-1 (IL-1) receptors significantly attenuated LPS-induced suppression of LH in gonadectomized male rats (Ebisui et al. 1992) supports a mechanism involving IL-1 $\beta$. As for the neural mechanism underlying LH suppression, LPS acutely suppressed the coordinated release of both gonadotropin-releasing hormone (GnRH) and LH pulses in ovariectomized (OVX) sheep, suggesting central inhibition of the GnRH pulse generator (Battaglia et al. 1998). The current hypothesis for GnRH pulse generation involves intrinsic activity of a highly interconnected population of cells in the arcuate nucleus of the hypothalamus that produce the neuropeptides kisspeptin (encoded by Kiss1), neurokinin B (NKB, encoded by Tac2) and dynorphin (encoded by pDyn), and are therefore referred to as KNDy neurons (Goodman et al. 2007). In support of the hypothesis that immune stress suppresses KNDy cell function, LPS reduced Kiss1 mRNA in the ARC nucleus in estradiolreplaced OVX rats (Kinsey-Jones et al. 2009).

LPS or IL-1 $\beta$ alone initiate similar patterns of neural activation following peripheral administration. Using c-Fos as a marker of neuronal activation, robust activation was observed following LPS or IL- $1 \beta$ within the area postrema and norepinephrine-containing brainstem regions, as well as select hypothalamic nuclei associated with both HPA and reproductive axis function, including the paraventricular nucleus and dorsomedial nucleus (Schiltz \& Sawchenko 2007). IL-1 receptors are located within the area postrema, a circumventricular organ with a rarefied blood-brain barrier, which is well-positioned to be responsive to altered circulating cytokine levels (Ericsson et al. 1994). Indeed, lesioning of either the area postrema or the nucleus of the solitary tract (NTS) brainstem region has been shown to prevent activation of the HPA axis activity by IL-1 $\beta$ (Lee et al. 1998, Buller et al. 2001). However, a peripheral mechanism that cannot be overlooked, since subdiaphragmatic vagotomy also prevents HPA axis activation in response to IL-1 $\beta$ (Hansen et al. 1998). Collectively, both the vagus nerve and brainstem appear to be integral sites involved in transmitting cytokine signals and mediating neuroendocrine responses to peripheral immune/inflammatory stress.

The present study tested the hypothesis that peripheral IL-1 $\beta$ impairs reproductive neuroendocrine function via activation of cell populations within the brainstem and inhibition of arcuate KNDy neurons. Bolus administration of IL-1 $\beta$ was employed as a prototypic inflammatory mediator, which would permit temporal evaluation of body-to-brain signaling in the absence of secondary cytokine effects that would be generated by LPS. The role of estradiol was considered as IL- $1 \beta$, has been shown to block the estradiol-induced LH surge in females rats (MohanKumar \& MohanKumar 2002), but was ineffective in reducing mean LH in gonadectomized male rats (Rivier \& Vale 1989, Rivest et al. 1992). Moreover, estradiol has long been recognized to enhance stress responsivity in females (Chen et al. 1992), and more recently was shown to enhance the suppression of LH by corticosterone (Kreisman et al. 2019) and prolactin (Silva et al. 2020). Here, we present a series of functional and anatomical experiments conducted in female mice, with and without estradiol replacement, to dissect the neural sites involved in the inhibitory effect of acute IL- $1 \beta$ on pulsatile LH secretion.

\section{Materials and methods}

\section{Animals}

Adult female C57BL/6 (Envigo; Indianapolis, IN, USA) and Kiss1hrGFP mice (Cravo et al. 2013) (8-14 week old) were housed two per cage under standard conditions under a 12-h light, 12-h dark cycle with lights on at 06:00 h. Animals had ad libitum access to water and Harlan irradiated chow \#2920X at a University of California, San Diego vivarium. All surgeries and pulse blood sampling periods were performed between 08:00 $\mathrm{h}$ and 15:00 h. Pulse bleeds were initiated at 09:30 h. This study and all animal procedures were approved by the University of California, San Diego Institutional Animal Care and Use Committee and were performed in accordance with the National Institutes of Health guidelines for the care and use of research animals.

Ten to twelve days prior to experimentation, mice were OVX aseptically under isoflurane anesthesia and were implanted subcutaneously with a silastic capsule containing either sesame oil (Millipore Sigma; OVX+oil group) 
or 100 ng 17 -estradiol (Millipore Sigma; OVX +E2 group) dissolved in sesame oil, as described previously (Kreisman et al. 2019). This estradiol dose approximates a diestrouslike level based on uterine weight values. Following euthanasia, the uterus was dissected and weighed to confirm the efficacy of the estradiol treatment. For 5 weeks prior to experimentation, mice were handled daily and sham injected to acclimatize the animals to the tail-bleed sampling and intraperitoneal (i.p.) administration, as published previously (Yang et al. 2017, McCosh et al. 2018).

\section{Experimental designs}

In experiment 1 , whole blood samples were collected for measurement of LH from the tail of OVX + oil or OVX + E2 C57BL/6 female mice prior to and following IL-1 $\beta$ $(20 \mu \mathrm{g} / \mathrm{kg}$, human recombinant, Millipore Sigma, SRP3083) or vehicle $(0.05 \% \mathrm{BSA}$ in saline) administered via ip injection ( $n=8-11 /$ group). This dose of IL-1 $\beta$ suppressed steroid-induced LH surges in female rats (MohanKumar \& MohanKumar 2002) and is within the range of doses which elicits HPA axis activation (Ericsson et al. 1994, Matsuwaki et al. 2014). Biological efficacy of IL-1 $\beta$ was determined by confirming elevated corticosterone at $\sim 60$ min post injection in additional OVX + oil or OVX $+\mathrm{E} 2$ females (data not shown). To ensure that all animals were expressing LH pulses prior to treatment, five samples were collected at 12-min intervals for $60 \mathrm{~min}$ prior to treatment with IL-1 $\beta$ or vehicle. These five samples were averaged as the pre-treatment mean. Samples were then collected for LH at hourly intervals following treatment with IL-1 $\beta$ or vehicle.

In experiment 2, serial blood samples were collected at 12-min intervals from the tail of $\mathrm{OVX}+\mathrm{E} 2 \mathrm{C} 57 \mathrm{BL} / 6$ females for measurement of pulsatile LH from $\sim 90 \mathrm{~min}$ before to $180 \mathrm{~min}$ following the administration of IL- $1 \beta$ or vehicle ( $n=5-7 /$ group). The 12-min sampling frequency was chosen to enable a 270-min period of observation, which is a long period of LH pulse monitoring in the mouse, and was influenced by our observation in experiment 1 which indicated a suppression of $\mathrm{LH}$. We have previously monitored $\mathrm{LH}$ pulses in $\mathrm{OVX}+\mathrm{E} 2$ females with a 6-min sampling frequency and acknowledge that a 12-min sampling interval would increase the probability of not detecting higher-frequency pulses (Kreisman et al. 2019).

In experiment 3, tail blood samples were collected $10 \mathrm{~min}$ before and $10 \mathrm{~min}$ following injection with kisspeptin (2 mg/kg, ip; ThermoFisher) from OVX+E2
C57BL/6 females treated with IL-1 $\beta$ or vehicle $(n=7 /$ group) 120 min earlier, as previously published (McCosh et al. 2019). The timing of blood collection is optimal for maximal LH release in response to this dose and route of kisspeptin administration (Tonsfeldt et al. 2019).

In experiment $4, \mathrm{OVX}+\mathrm{E} 2 \mathrm{Kiss} 1 \mathrm{hrGFP}$ females were euthanized $2 \mathrm{~h}$ following IL- $1 \beta$ or vehicle ( $n=3-4$ /group) administration with an overdose of pentobarbital (Fatal Plus, MWI Animal Health, Boise, ID, USA) and perfused by cardiac puncture with $4 \%$ paraformaldehyde in phosphatebuffered (PB) saline (PBS). Following collection, brains were stored overnight in $4 \%$ paraformaldehyde and then transferred to $30 \%$ sucrose in PB for at least 1 day until processing for immunohistochemistry.

In experiment 5, C57BL/6 OVX +oil and OVX $+\mathrm{E} 2$ ( $n=4-5$ /group) females were euthanized under isoflurane via rapid decapitation. The brain was collected and immediately frozen on dry ice. Samples were stored at $-80^{\circ} \mathrm{C}$ until RNA extraction and gene expression analysis.

In experiment 6 , fixed neural tissue from OVX+oil and OVX+E2 C57BL/6 ( $n=3-7 /$ group) females was collected $2 \mathrm{~h}$ following IL-1 $\beta$ or vehicle and processed for immunohistochemistry as described in experiment 4 .

\section{Ultrasensitive mouse LH enzyme-linked immunosorbent assay}

Whole blood $(3 \mu \mathrm{L})$ samples for measurement of LH were immediately diluted (1:20) into $57 \mu \mathrm{L}$ of assay buffer, mixed, and placed on ice until storage at $-20^{\circ} \mathrm{C}$ (Yang et al. 2017, McCosh et al. 2019). LH was measured in singlicate by ELISA at the University of Virginia Ligand Assay Core, based on a method and reagents published in Steyn et al. (2013). The limit of quantitation (functional sensitivity) is defined as the lowest concentration that demonstrates accuracy within $20 \%$ of expected values and intraassay coefficient of variation $(\% \mathrm{CV})<20 \%$ and was determined by serial dilutions of a defined sample pool. Functional sensitivity was $0.320 \mathrm{ng} / \mathrm{mL}$. Intra- and inter-assay \%CVs were $<2.3$ and $<7 \%$, respectively.

The criteria for LH pulse detection was similar to the three criteria proposed by Goodman \& Karsch (1980). (1) The pulse peak must be within three data points from the preceding nadir, (2) the amplitude must be greater than the sensitivity of the assay, and (3) the amplitude must also be three standard deviations above the variability of the assay. Pulse frequency was defined as the number of pulses in each 84-min period. Mean LH was calculated by averaging all LH values in each sampling period. Pulse amplitude was calculated as the difference from the 
pulse peak to the preceding nadir, and an average pulse amplitude value for each animal during the pre- and postsampling period was determined. Average values for pulse frequency, mean LH, and pulse amplitude were calculated across three 84-min time periods ( -84 to $0 \mathrm{~min}$ vs 12 to $96 \mathrm{~min}$ vs 96 to $180 \mathrm{~min}$ ) and evaluated by repeatedmeasures two-way ANOVA followed by Tukey's HSD test to determine significant differences due to treatment with IL-1 $\beta$ across time periods. All statistical analyses were performed using JMP 10.0.0 (SAS Institute) and statistical significance was defined as $P<0.05$.

\section{Immunohistochemistry (IHC)}

\section{IHC for GFP (Kiss1) and c-Fos}

One series of $40 \mu \mathrm{m}$ sections, encompassing the entire arcuate nucleus, was processed for each $\mathrm{OVX}+\mathrm{E} 2$ Kiss1hrGFP animal. The following steps were performed at room temperature with gentle agitation, unless noted otherwise. Tissue was rinsed in $\mathrm{PB}, 12$ times for $15 \mathrm{~min}$, and incubated overnight at $4^{\circ} \mathrm{C}$. The next day, tissue was rinsed six times in $\mathrm{PB}$ and then six times in PBS, for $5 \mathrm{~min}$ each (the following rinsing steps were performed in PBS). Antigen retrieval was performed by incubating tissue in boiling citra buffer (NC9935936, ThermoFisher) for 10 min, twice. Next, tissue was rinsed and then incubated in blocking solution, containing PBS with $0.4 \%$ Triton $\mathrm{X}-100$ and $4 \%$ NGS, for $1 \mathrm{~h}$. Tissue was then incubated in rabbit anti-c-Fos (1:1000, \#2250; Cell Signaling) in blocking solution for $18 \mathrm{~h}$ at $4^{\circ} \mathrm{C}$. This c-Fos primary antibody was validated previously for use in mouse neural tissue by confirming that omission produced no specific staining (Baur et al. 2018). The next day tissue was rinsed and then incubated with Alexa Fluor 555 goat anti-rabbit (Life Technologies). Tissue was rinsed and incubated in blocking solution for $1 \mathrm{~h}$ and incubated in rabbit antiGFP conjugated to Alexa 488 (1:1000, Life Technologies) in blocking solution for $18 \mathrm{~h}$ at $4^{\circ} \mathrm{C}$. We have previously shown that application of this anti-GFP antibody to wildtype tissue resulted in no specific staining (Kreisman et al. 2019). Finally, tissue was rinsed, mounted on Superfrost slides, coversliped with gelvatol (Harlow \& Lane 2006), and stored at $4^{\circ} \mathrm{C}$ until microscopy.

\section{IHC for c-Fos}

Fixed tissue from C57BL/6 mice was sectioned $(40 \mu \mathrm{m})$ on a cryostat in three series and stored in cryoprotectant solution. One series of $40 \mu \mathrm{m}$ sections, encompassing the entire brain, was processed for each animal. The following steps were performed at room temperature with gentle agitation, unless noted otherwise. Tissue was rinsed in $\mathrm{PB}, 12$ times for $15 \mathrm{~min}$, and incubated overnight at $4^{\circ} \mathrm{C}$. The next day, tissue was rinsed six times in $\mathrm{PB}$ for 5 min and then six times in PBS for 5 min each (the following rinsing steps were performed in PBS). Antigen retrieval was performed by incubating tissue in boiling citra buffer for $10 \mathrm{~min}$, twice. Tissue was rinsed and incubated in $0.3 \%$ hydrogen peroxide in PBS for $10 \mathrm{~min}$. Next, tissue was rinsed and then incubated in blocking solution, containing PBS with $0.4 \%$ Triton X-100 and 4\% NGS, for $1 \mathrm{~h}$. Tissue was then incubated in rabbit anti-cFos (1:18,000, Millipore Sigma, ABE45; lot: 3088370) in blocking solution for $18 \mathrm{~h}$ at $4^{\circ} \mathrm{C}$, as previously described and validated (i.e. primary antibody omission) for use in our laboratory (Kreisman et al. 2019, McCosh et al. 2019). Note, during the course of this study the Millipore Sigma (ABE45) c-Fos antibody became unavailable, which necessitated the use of two different c-Fos antisera. The next day tissue was rinsed and then incubated with biotinylated goat anti-rabbit antisera in blocking solution (1:500, Vector Laboratories) for $1 \mathrm{~h}$. Next, tissue was rinsed and then signal was amplified with Vectastain Elite ABC Kit (1:500, Vector Laboratories), in PBS for $1 \mathrm{~h}$. Tissue was rinsed and then incubated with biotinylated tyramine for amplification (1:250, Perkin Elmer Inc) in PBS containing $0.003 \%$ hydrogen peroxide for $10 \mathrm{~min}$. Tissue was rinsed and incubated with streptavidin conjugated to DyLight 488 (1:200, Invitrogen) in PBS. Finally, tissue was rinsed, mounted on Superfrost slides, coverslipped with gelvatol (Harlow \& Lane 2006), and stored at $4^{\circ} \mathrm{C}$ until microscopy.

\section{Imaging}

Imaging was performed with a Nikon Ti2-E inverted microscope with DS-Qi2 monochrome CMOS camera controlled with NIS elements. All cell counting was done by an observer blinded to treatment group using ImageJ software (Schindelin et al. 2012), following minor adjustments to brightness and contrast. For single-label c-Fos, the number of c-Fos immunoreactive nuclei in 2-6 hemisections per region or 1-2 sections for area postrema was determined in the individual brain regions for each animal by an observer blinded to treatment. The mean number of c-Fos cells per hemisection or section was compared between groups (vehicle vs IL-1 $\beta$ ) and across steroid treatments (oil vs E2) using two-way ANOVA followed by Tukey's HSD test.

For GFP (Kiss1) and c-Fos IHC, at least two hemisections from each of three arcuate regions were selected for analysis (i.e. rostral, middle, and caudal). Within each 
region of the arcuate, the total number of GFP-labeled Kiss1 cells and the percentage of GFP-labeled cells that contained c-Fos, were determined in each hemisection. The mean \pm s.E.M. number of GFP-labeled Kiss1 cells per hemisection and mean percentage of GFP-labeled Kiss1 cells that contained c-Fos is reported. Student's $t$-test was used to compare the total number of GFP-labled cells and the percentage of GFP-labled cells that contained c-Fos cells between treatments.

\section{RNA isolation and gene expression analysis}

Brains were sectioned coronally $(250 \mu \mathrm{m})$ on a cryostat at $-10^{\circ} \mathrm{C}$. Sections and semicircular micropunches, $2 \mathrm{~mm}$ in diameter, encompassing the area postrema and NTS were collected from -6.96 to $-7.92 \mathrm{~mm}$ from bregma, according to a mouse brain atlas and stored at $-80^{\circ} \mathrm{C}$ (Franklin \& Paxinos 2013). RNA was isolated from area postrema/NTS brainstem punches using the RNAqueous Micro Kit (Life Technologies, Ambion), per manufacturer's instructions. After RNA isolation, DNA contamination was removed with DNA-free DNase treatment (Life Technologies, Ambion) and RNA was confirmed for purity $\left(\mathrm{A}_{260}: \mathrm{A}_{280}\right.$ ratio of 2.0-2.1) and quantified by nanodrop. Using the iScript cDNA synthesis kit (Bio-Rad) $500 \mathrm{ng}$ of RNA was reverse transcribed. For quantitative PCR (qPCR), cDNA and gene-specific primers were loaded according to Table 1, along with SYBR green (Bio-Rad). The subsequent data were analyzed using the comparative cycle threshold $\left({ }^{\Delta \Delta} \mathrm{Ct}\right.$ ) method (Livak \& Schmittgen 2001) with Gapdh as a reference gene, as it displayed transcriptional stability across samples and treatments. Student's $t$-test was used to determine significant differences in ${ }^{\Delta} \mathrm{C}$-relative quantity across groups $(\mathrm{OVX}+$ oil vs $\mathrm{OVX}+\mathrm{E} 2)$.

\section{Results}

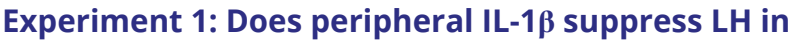 female mice?}

Figure $1 \mathrm{~A}$ presents $\mathrm{LH}$ values following IL-1 $\beta$ or vehicle as a percent of pretreatment mean to normalize values across estradiol treatments. Analysis via three-way repeated measures ANOVA identified a trending suppression in LH values $(P=0.058$, treatment $\times$ time $\times$ estradiol status $)$. In order to evaluate mean LH levels within estradiol treatment groups, LH values were log-transformed and analyzed. In OVX+oil mice, LH did not significantly differ over time in response to IL-1 $\beta$ or vehicle (Fig. 1B; treatment $\times$ time, $P=0.078$ ). However, IL- $1 \beta$ induced a significant suppression of mean LH following IL-1 $\beta$ in OVX +E2 animals (Fig. 1C; treatment $\times$ time, $P<0.05$ ), with significance identified at 120 and 180 min compared to vehicle-treated OVX $+\mathrm{E} 2$ controls (Fig. 1C, $P<0.05$ ).

\section{Experiment 2: Is pulsatile LH impaired by IL-1 $\beta$ in OVX + E2 female mice?}

Representative profiles of pulsatile $\mathrm{LH}$ are depicted for three OVX +E2 mice treated with either vehicle (Fig. 2A, B and C) or IL-1 $\beta$ (Fig. 2D, E and F). Figure 3 illustrates group mean values and the results of the statistical analysis. A significant treatment $\times$ time interaction $(P<0.05)$ was identified for LH pulse frequency (Fig. 3A), but not for pulse amplitude (Fig. 3B). Post hoc assessment revealed that IL-1 $\beta$ significantly reduced LH pulse frequency over time (Fig. 3A, $P<0.05$ ), whereas frequency was not significantly altered by vehicle over time. Although the analysis identified this significant effect of IL- $1 \beta$ on pulse frequency over time, values did not differ between treatments at individual time points. Mean LH trended lower in OVX+E2 mice treated with IL-1 $\beta$ (Fig. 3C, $P=0.066)$.

\section{Experiment 3: Does IL-1 $\beta$ impair the LH response to kisspeptin?}

Table 2 details the LH response in tail blood samples collected $10 \mathrm{~min}$ before and $10 \mathrm{~min}$ following injection with kisspeptin $(2 \mathrm{mg} / \mathrm{kg}$, ip) from $\mathrm{OVX}+\mathrm{E} 2$ animals treated with IL-1 $\beta$ or vehicle 120 min earlier. In vehicletreated $\mathrm{OVX}+\mathrm{E} 2$ females, the average increase in $\mathrm{LH}$ was $5.2 \pm 0.6 \mathrm{ng} / \mathrm{mL}$. The LH response to kisspeptin was also robust $(4.8 \pm 0.6 \mathrm{ng} / \mathrm{mL})$ in $\mathrm{OVX}+\mathrm{E} 2$ females treated with IL-1 $\beta$, but did not significantly differ from vehicle-treated controls $(P>0.05)$.

Table 1 Primer sequences for qPCR.

\begin{tabular}{|c|c|c|}
\hline Gene & Forward sequence & Reverse sequence \\
\hline Gapdh & TGCACCACCAACTGCTTAG & GGATGCAGGGATGATGTTC \\
\hline$\| 1-1 r$ & GCACGCCCAGGAGAATATGA & AGAGGACACTTGCGAATATCAA \\
\hline$E r \alpha$ & GCGCAAGTGTTACGAAGTG & TTCGGCCTTCCAAGTCATC \\
\hline
\end{tabular}



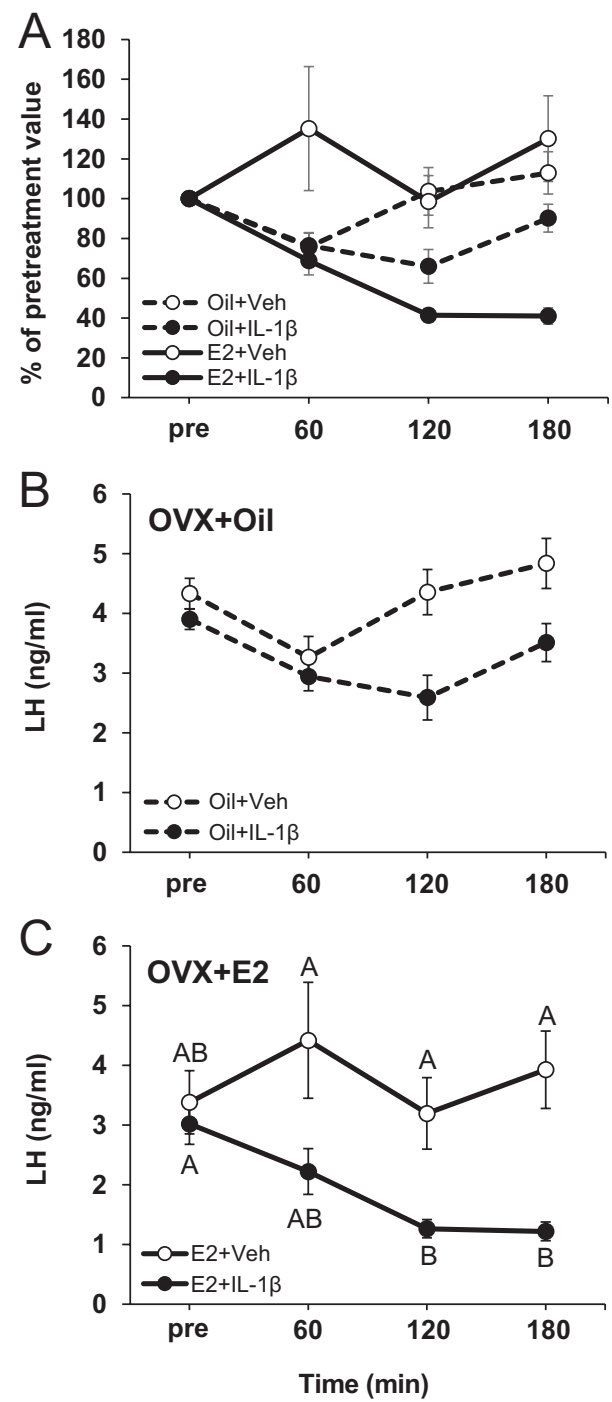

\section{Figure 1}

LH values in OVX mice treated with $100 \mathrm{ng}$ estradiol (E2, solid lines) or oil (dashed lines) prior to and following IL-1 $\beta$ (closed circles) or vehicle (open circles). (A) Values are expressed as percent of pretreatment mean for each individual animal (mean \pm S.E.M.; three-way repeated-measures ANOVA, $P=0.058$ ). The pre value represents an average of five $\mathrm{LH}$ samples collected at 12-min intervals to ensure all animals are expressing $\mathrm{LH}$ pulses prior to treatment. Mean ( \pm S.E.M.) LH concentrations in OVX mice treated with oil ( $\mathrm{B}, n=8 /$ group) or E2 (C, $n=8-11 /$ group) prior to and following IL-1 $\beta$ (closed circles) or vehicle (open circles). Data points are fitted with lines graphically determined by Microsoft Excel v.10. Data points that do not share any common letters signify significant differences across time and treatments of log-transformed mean $\mathrm{LH}$ levels (two-way repeated-measures ANOVA, $P<0.05$ ).

\section{Experiment 4: Does IL-1ß impair arcuate Kiss1 neuronal activation?}

Representative images of c-Fos within GFP-labeled arcuate Kiss1 cells and summary statistics in OVX +E2 animals treated with vehicle $(\mathrm{A}-\mathrm{C})$ or IL-1 $\beta$ (D-F) are shown in Fig. 4. The average number of GFP-labeled Kiss1 cells
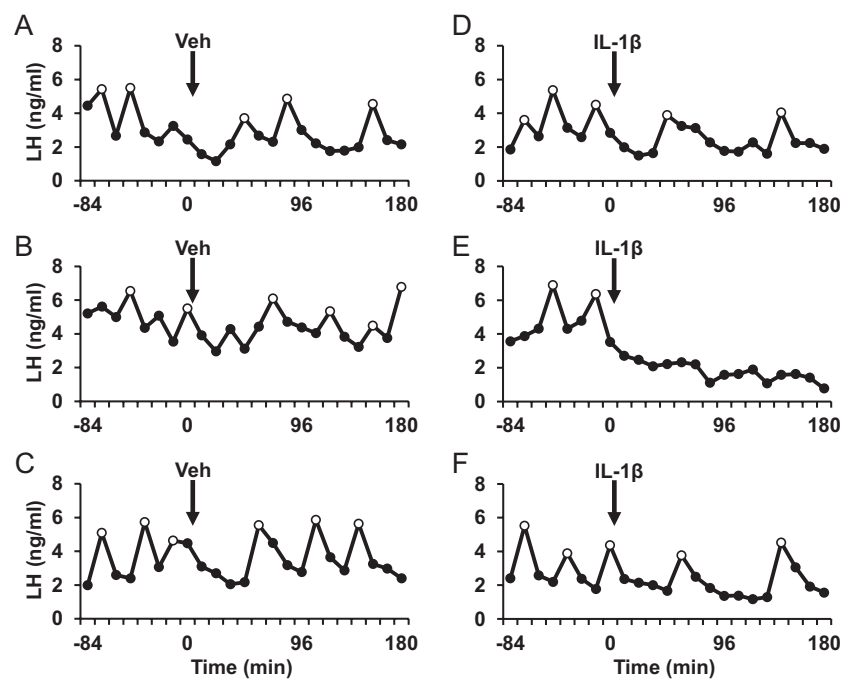

Figure 2

Patterns of pulsatile $\mathrm{LH}$ secretion in representative OVX + E2 mice treated with either vehicle (A, B and C) or IL-1 $\beta$ (D, E and F; $20 \mu \mathrm{g} / \mathrm{kg}$, ip) at time 0 . Time of injection with vehicle or IL-1 $\beta$ is designated by the arrow ( $0 \mathrm{~min})$. $\mathrm{LH}$ pulses are identified by open circles.

across the rostral, medial and caudal arcuate did not differ between animals treated with IL-1 $\beta$ compared to vehicle controls (Fig. 4G). In contrast, across all three regions of the arcuate, IL-1 $\beta$ caused a significant reduction in the percentage of GFP-labeled Kiss1 cells that contained c-Fos (Fig. 4H).

\section{Experiment 5: Does estradiol increase IL-1 receptor levels within the brainstem?}

In order to identify a potential pathway whereby estradiol enhances IL-1 $\beta$-inhibition of arcuate Kiss1 cells, we assessed IL-1 receptor (Il-1r) levels within the brainstem and performed immunohistochemistry of neural targets using c-Fos as a marker for cellular activation. Gene expression for $\mathrm{Il}-1 \mathrm{r}$ receptor with the area postrema/ NTS was evaluated in micropunches of brainstem tissue collected from $\mathrm{OVX}+$ oil or $\mathrm{OVX}+\mathrm{E} 2$ mice. Estradiol elicited a significant increase in $I l-1 r$ and $E r \alpha$ mRNA within the area postrema/NTS regions (Fig. 5).

\section{Experiment 6: Does estradiol enhance the neural

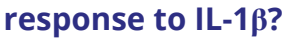

Figure 6 shows representative photomicrographs of nuclear c-Fos in C57BL6 animals within neurons located in the area postrema, NTS, ventrolateral medulla, paraventricular nucleus and dorsomedial nucleus in fixed brain tissue collected $2 \mathrm{~h}$ following vehicle 

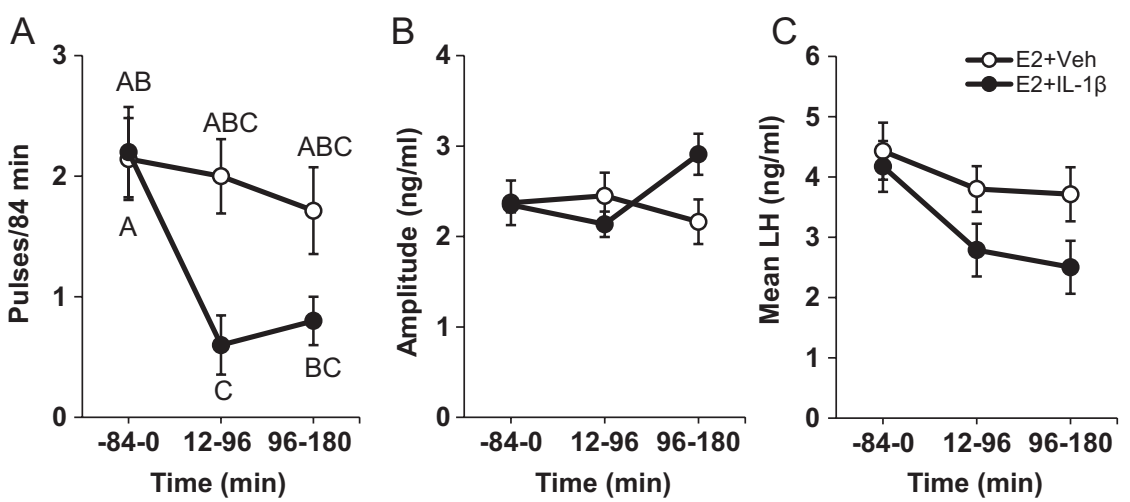

\section{Figure 3}

Mean ( \pm S.E.M.) pulse frequency (A), pulse amplitude (B), and $\mathrm{LH}(\mathrm{C})$ compared across time (84-min periods) in OVX + E2 mice treated with vehicle (open circles) or IL-1 $\beta$ (closed circles, $n=5-7$ /group). Data points that do not share any common letters signify significant differences across time and treatments (two-way repeated measures ANOVA, $P<0.05$ )
(Fig. 6A, B, C, D and E) or IL-1 $\beta$ (Fig. 6F, G, H, I and J). IL-1 $\beta$ induced a significant increase in c-Fos-containing cells in all regions examined (Fig. 6K, L, M, N and O), however, the c-Fos response did not differ across estradiol treatments $(P>0.05$, no treatment $\times$ group interaction). Interestingly, estradiol did increase basal state c-Fos in the NTS of vehicle-treated OVX + E2 females (Fig. 6L, $P<0.05$ ).

\section{Discussion}

In the current study we investigated the neural mechanism whereby a peripheral (ip) inflammatory challenge acutely disrupts gonadotropin secretion. We demonstrate that administration of peripheral IL-1 $\beta$ is sufficient to impair pulsatile LH secretion, but that this inhibitory response is dependent on the presence of estradiol in the female mouse. Reduced c-Fos expression in arcuate Kiss1 neurons coupled with a normal LH response to kisspeptin suggests that the suppression of pulsatile LH occurs as a result of impaired KNDy neuron activity, and not due to downstream impairment of GnRH neuron or gonadotrope cell function. Using c-Fos as a marker for cellular activation, we identify specific brain regions activated by IL- $1 \beta$, which may play a role in the suppression of LH pulsatility during acute inflammatory stress. We demonstrate that both Er $\alpha$ and Il-1r mRNA expression in the area postrema/NTS brainstem region is elevated by a low physiologic level of estradiol,

Table 2 Effect of IL-1 $\beta$ on LH response to kisspeptin (Experiment 3).

\begin{tabular}{|c|c|c|}
\hline & \multicolumn{2}{|c|}{ LH response to kisspeptin $(2 \mathrm{mg} / \mathrm{kg}$, ip) } \\
\hline & Pre kissa & 10 min Post kiss \\
\hline E2 + Vehicle & $1.46 \pm 0.21$ & $6.66 \pm 0.47 b$ \\
\hline $\mathrm{E} 2+\mathrm{IL}-1 \beta$ & $1.25 \pm 0.21$ & $6.05 \pm 0.63^{b}$ \\
\hline
\end{tabular}

aValues are mean \pm S.E.M.. 'Treatment effect as determined by ANOVA $(P<0.05)$; no treatment $\times$ group interaction. providing a mechanism whereby the response to IL-1 $\beta$ is enhanced by this ovarian steroid. Taken together, these data support the working hypothesis that peripheral IL-1 $\beta$ impairs gonadotropin secretion in female mice via a neural mechanism that involves IL-1 receptor-responsive brainstem neurons in the area postrema/NTS which signal to arcuate KNDy neurons that control GnRH and LH pulsatility.

Our study expands upon what was previously known regarding the inhibitory effect of an immune/ inflammatory stress on LH secretion by identifying arcuate KNDy cells as a critical component of this pathway. Hypothalamic-pituitary portal sampling in the sheep model demonstrated that LPS reduced the coordinated release of both GnRH and LH pulses in OVX females, suggesting central inhibition of LH secretion (Battaglia et al. 1998). Consistent with this, the suppression of pulsatile $\mathrm{LH}$ in OVX+E2-treated rats was associated with reduced Kiss1 expression in arcuate micropunches (Kinsey-Jones et al. 2009). Thus, our finding that IL-1 $\beta$ suppresses KNDy cell activation is in agreement with this prior work with LPS and reinforce the potential inhibitory role of IL-1 $\beta$ during the acute immune/inflammatory response to LPS, as previously shown (Ebisui et al. 1992). With regard to other mediators implicated in the reproductive response to LPS, enhanced glucocorticoid production is not required, but prostaglandin production has been shown to be necessary for the inhibitory effect of LPS on pituitary responsiveness to GnRH (Karsch et al. 2002). Considering the evidence that prostaglandins act peripherally to mediate LPS-induced secretion of cytokine production, prostaglandin and cytokine production may contribute to a shared pathway activated by LPS (Bour et al. 2000). Based on our findings that IL-1 $\beta$ inhibits LH secretion upstream of the GnRH and gonadotrope cell, we speculate that IL-1 $\beta$ and prostaglandins are each involved in the suppression of LH secretion during immune/ inflammatory stress. 

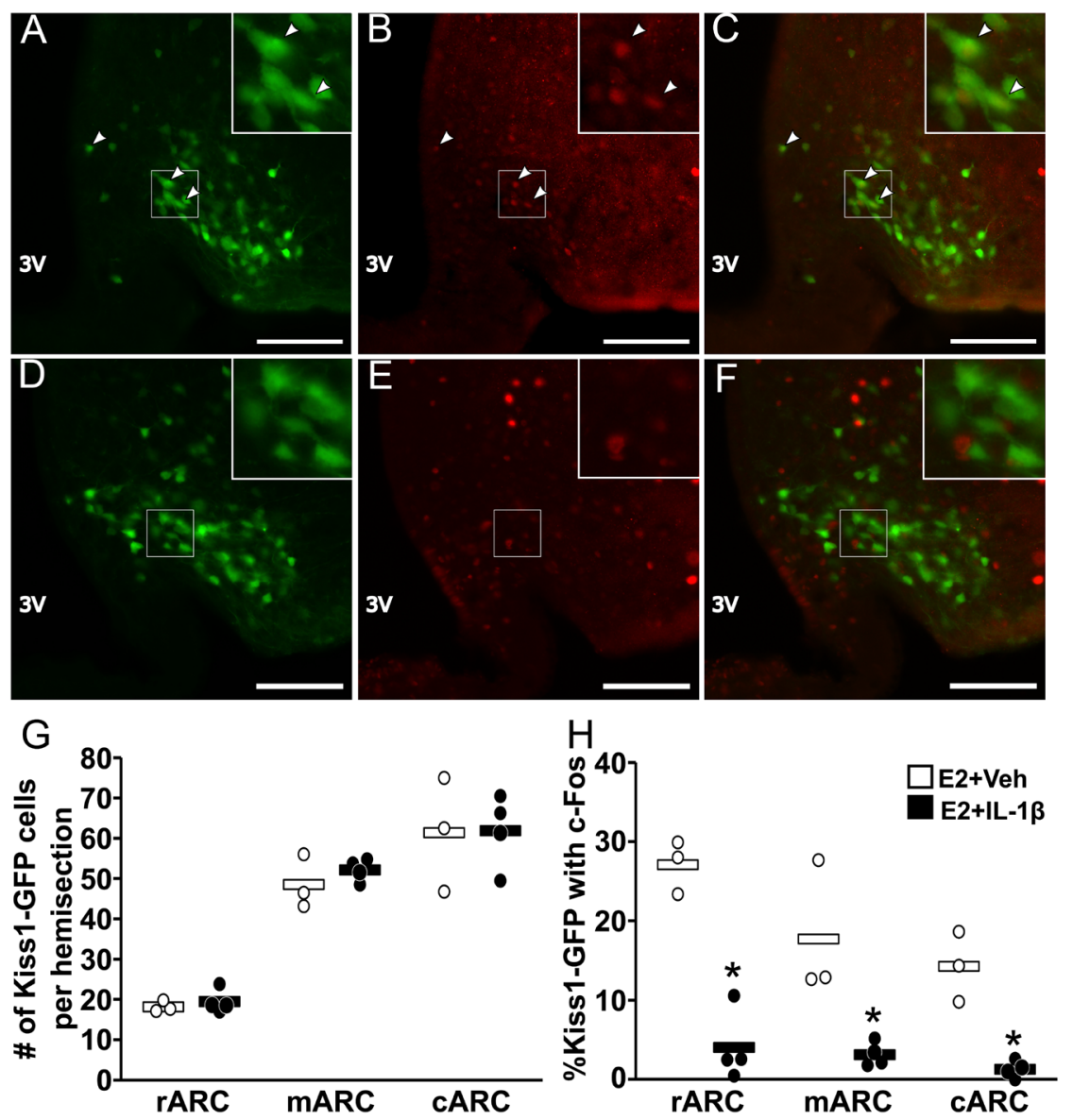

\section{Figure 4}

Representative photomicrographs of dual-labeled Kiss1hrGFP and c-Fos cells in the ARC of an $\mathrm{OVX}+\mathrm{E} 2$ female mouse treated with vehicle (A, B and $C$ ) or IL-1 $\beta$ (D, E and F). GFP-labeled Kiss1 cells $(A, D), C-F o s(B, E)$, and the merged images $(C, F)$ are shown (scale bar $=50 \mu \mathrm{m}$ ). White boxes indicate location of zoomed panels. White arrows indicate dual-labeled cells. Panels ( $G$ and $H$ ) show spread-plots of the data (points) and mean (horizontal bar) of the total number of Kiss1 hrGFP cells (G) and percentage of Kiss 1 hrGFP cells that contain c-Fos $(\mathrm{H})$ following vehicle (open) or IL-1 $\beta$ (closed). $n=3-4$ /group. ${ }^{*}$, significant effect of IL-1 $\beta$ $(P<0.05)$.

In addition, these findings suggest that the inhibition of LH secretion is enhanced by estradiol. On the one hand, our demonstration that ip IL-1 $\beta$ inhibits LH could be viewed as in contrast to previous reports that systemic

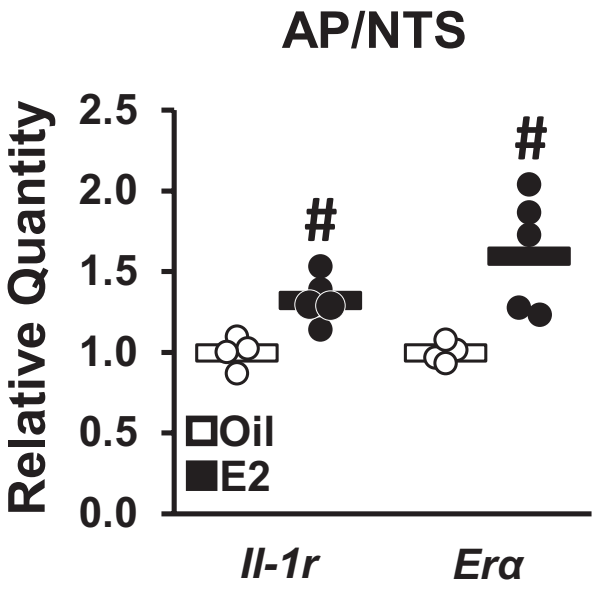

Figure 5

QPCR analysis of II-1r or Era gene expression in brain micropunches containing the AP/NTS collected from OVX + oil (open) or OVX + E mice (closed). Data are depicted as a spread-plot (points) and group mean (horizontal bar). $n=4-5$ /group. \#, effect of estradiol, $P<0.05$.
IL-1 $\beta$ administered via an i.v. route was insufficient to impair gonadotropin secretion; however, a number of experimental details differed between our study and those published previously which may explain the discrepancy. For example, earlier studies utilized gonadectomized males and monitored gonadotropin secretion with singlepoint hormone assessments (Rivier \& Vale 1989, Rivest et al. 1992). Due to variability in LH pulse dynamics between animals and variation in circulating levels during the pulse itself, inhibition can be less obvious when evaluating single-point measures. This is especially pertinent as our study implies the response to IL-1 $\beta$ is more robust in the presence of estradiol (OVX mice did show a trending suppression, $P=0.078$ ) and this effect of gonadal steroids to enhance suppression of LH may hold true in males, but requires further studies to tease out these additive effects of inhibitors of LH release. Of interest, an effect of estradiol to enhance LH suppression was recently shown in response to corticosterone (Kreisman et al. 2019) and prolactin (Silva et al. 2020). Based on our observations, we conclude that peripheral IL- $1 \beta$ reduces $\mathrm{LH}$ secretion by impairing the frequency of $\mathrm{LH}$ pulses in OVX + E2 females. 

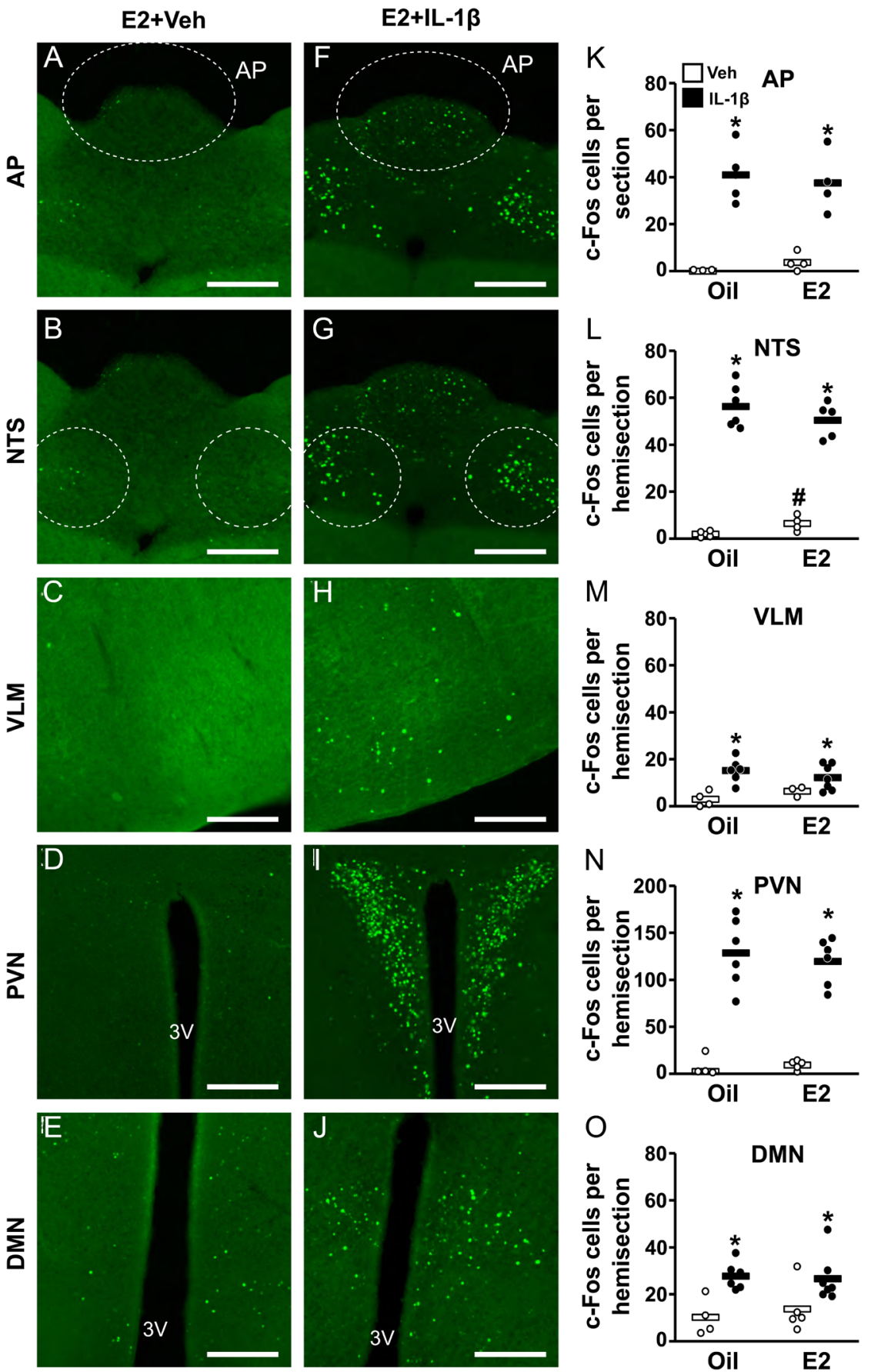

\section{Figure 6}

Representative photomicrographs depicting staining for c-Fos in the area postrema (AP), nucleus of the solitary tract (NTS), ventral lateral medulla (VLM), paraventricular nucleus (PVN), or dorsal medial nucleus (DMN) of OVX + E2 mice treated with vehicle (A, B, C, D and E) or IL-1 $\beta$ (F, G, $\mathrm{H}, \mathrm{I}$ and $\mathrm{J})$. Scale bar equals $100 \mu \mathrm{m}$. (K, L, M, N and O) Mean (horizontal bar) number of c-Fos cells per section or hemisection in $\mathrm{OVX}+$ oil vs $\mathrm{OVX}+\mathrm{E} 2$ mice treated with vehicle (open) or IL-1 $\beta$ (closed). $n=3-7 /$ group. \#, effect of estradiol; *, significant effect of IL-1 $\beta(P<0.05)$; no treatment $\times$ estradiol status group interaction.

Multiple questions arise from the current study, including the identity of the cells responding to peripheral IL-1 $\beta$ and the pathway underlying KNDy suppression. One important neural site to consider is the area postrema, a circumventricular organ with a weak blood-brain barrier, which could allow IL-1 $\beta$ to initiate neural signaling directly within this region. Area postrema lesions reduce IL-1 $\beta$-induced HPA axis activation (Ishizuka et al. 1997), identifying this region as important for this aspect of neuroendocrine regulation in response to immune/ inflammatory stress. Our findings demonstrating that $I l-1 r$ is expressed in a brainstem area containing the area postrema and that this region expresses neuronal activation in response to IL- $1 \beta$ support the possibility of direct actions of peripheral IL- $1 \beta$ within this neural site. Dense neural projections exist from the area postrema to the NTS and from the NTS to the ventral lateral medulla (van der Kooy \& Koda 1983, Cunningham et al. 1994) and 
in mediating the response to systemic IL-1 $\beta$ (Ishizuka

activation of these norepinephrine neuron populations have been demonstrated in rats in response to IL- $1 \beta$ (Ericsson et al. 1994, Buller et al. 2001). How this signal is conveyed to arcuate KNDy cells, however, remains unclear. NTS neurons project broadly throughout the hypothalamus, but may not directly innervate the arcuate hypothalamus (Sawchenko \& Swanson 1982). Recent tracing studies in which a retrograde tracer was delivered to arcuate KNDy neurons failed to reveal labeled neural inputs originating from the brainstem (Moore et al. 2019, Yeo et al. 2019), implicating an indirect pathway connecting these two brain regions. Clearly, future work is warranted to determine the neural pathway underlying the reproductive impairment by IL- $1 \beta$ and determine whether the cellular mechanism is common between ip vs iv activation of the HPA and reproductive axes.

Another question that remains outstanding is the mechanism whereby estradiol enhances the suppressive effect of peripheral IL-1 $\beta$. Based on our hypothesis that IL-1 $\beta$ is sensed in the brainstem, we tested the hypothesis that estradiol enhances the response of this neural site to IL-1 $\beta$, using c-Fos as a marker of neural activation. Contrary to our hypothesis, we did not observe an increase in IL-1 $\beta$-induced c-Fos within brainstem regions in estradiol-treated mice. This finding is cautioned by the caveat that c-Fos, although widely used, may not be a sufficiently sensitive marker to test this hypothesis. On the other hand, our finding that Il-1r expression is increased by estradiol within the area postrema/NTS causes us to speculate that estradiol may influence neural communication stemming from this brain locus during immune challenge with IL-1 $\beta$.

Another possibility for transmission of the IL- $1 \beta$ signal is the vagus nerve which is known to signal to the brain via neural connections within the area postrema, NTS and ventral lateral medulla brainstem nuclei (Ishizuka et al. 1997). In addition, vagal afferents projecting to brainstem autonomic areas are differentially affected by circulating levels of estrogen (Ciriello \& Caverson 2016). Thus, estradiol may influence the LH response to IL-1 $\beta$ via input of peripheral cytokine receptors found in the gut and intestines (McEntee et al. 2019). These abdominal organs are well-positioned to signal to the vagus nerve during an immune/inflammatory challenge, particularly when administered via an ip route, as used here. In support of this hypothesis, we found a significant elevation in $\mathrm{Il}-1 \mathrm{r}$ mRNA in the small intestine of animals treated with estradiol (data not shown). Evidence that vagotomy prevents ip IL-1 $\beta$-induced norepinephrine release in the paraventricular nucleus, further implicates the vagus nerve et al. 1997). Clearly, the interaction of estradiol and vagal afferent nerves during systemic immune/inflammatory challenge remain as an intriguing and important area of study.

In summary, we demonstrate that acute inflammatory stress suppresses pulsatile LH secretion in female mice and that this impairment involves inhibition of arcuate Kiss1 neuron function. Moreover, the inhibition of LH is enhanced by estradiol. These data provide strong rational for the investigation of neural populations afferent to arcuate Kiss1 cells that may be responsible for the suppression of pulsatile LH secretion during acute inflammatory stress. Considering that a number of diseases are associated with disrupted fertility and altered circulating inflammatory factors, such as polycystic ovarian syndrome, endometriosis, autoimmune disorders, and diabetes, these findings highlight the importance of understanding the pathway whereby peripheral inflammatory mediators disrupt reproductive neuroendocrine function and how estradiol alters these pathways.

\section{Declaration of interest}

The authors declare that there is no conflict of interest that could be perceived as prejudicing the impartiality of the research reported.

\section{Funding}

This work was supported by NIH grant R01 HD086100 and the UCSD Health Sciences Senate. K N M was supported by the Animal Care Program at UC San Diego. R B M was supported by NIH grant F32 HD096811 and T32 HD007203. Serum hormone assays were performed by The University of Virginia Ligand Assay Core Laboratory, which is supported through National Institute of Child Health and Human Development Grant P50 HD028934.

\section{Author contribution statement}

K N M, M J K, R B M and K M B designed the research study; K N M, M J K, $\mathrm{R} B \mathrm{M}, \mathrm{A} A \mathrm{R}$ performed the research; $\mathrm{K} \mathrm{N} \mathrm{M}$ and $\mathrm{M} \mathrm{J} \mathrm{K}$ analyzed the data; $\mathrm{KN} \mathrm{M}$ and $K \mathrm{M} \mathrm{B}$ wrote the paper, and $K N \mathrm{M}, \mathrm{MJ} \mathrm{K}, \mathrm{RB} \mathrm{M}, \mathrm{A} A \mathrm{R}$ and $\mathrm{KM} B$ edited and approved the manuscript.

\section{Acknowledgements}

The authors would like to thank Katherine Tian and Chloe Chan for helpful discussions and assistance with animal experiments. In addition, they would like to acknowledge Dr Carol Elias for her generous gift of the Kiss1 hrGFP mouse line and the Nikon Imaging Center at UC San Diego for access to microscopes and technical assistance with imaging. 


\section{References}

Battaglia DF, Brown ME, Krasa HB, Thrun LA, Viguie C \& Karsch FJ 1998 Systemic challenge with endotoxin stimulates corticotropin-releasing hormone and arginine vasopressin secretion into hypophyseal portal blood: coincidence with gonadotropin-releasing hormone suppression. Endocrinology 139 4175-4181. (https://doi.org/10.1210/ endo.139.10.6226)

Baur K, Hach A, Bernardi RE, Spanagel R, Bading H \& Bengtson CP 2018 c-Fos marking of identified midbrain neurons coactive after nicotine administration in-vivo. Journal of Comparative Neurology 526 2019-2031. (https://doi.org/10.1002/cne.24471)

Bour AM, Westendorp RG, Laterveer JC, Bollen EL \& Remarque EJ 2000 Interaction of indomethacin with cytokine production in whole blood. Potential mechanism for a brain-protective effect. Experimental Gerontology 35 1017-1024. (https://doi.org/10.1016/ s0531-5565(00)00128-5)

Buller K, Xu Y, Dayas C \& Day T 2001 Dorsal and ventral medullary catecholamine cell groups contribute differentially to systemic interleukin-1beta-induced hypothalamic pituitary adrenal axis responses. Neuroendocrinology 73 129-138. (https://doi. org/10.1159/000054629)

Chen MD, O’Byrne KT, Chiappini SE, Hotchkiss J \& Knobil E 1992 Hypoglycemic 'stress' and gonadotropin-releasing hormone pulse generator activity in the rhesus monkey: role of the ovary. Neuroendocrinology 56 666-673. (https://doi.org/10.1159/000126291)

Ciriello J \& Caverson MM 2016 Effect of estrogen on vagal afferent projections to the brainstem in the female. Brain Research $\mathbf{1 6 3 6}$ 21-42. (https://doi.org/10.1016/j.brainres.2016.01.041)

Cravo RM, Frazao R, Perello M, Osborne-Lawrence S, Williams KW, Zigman JM, Vianna C \& Elias CF 2013 Leptin signaling in Kiss1 neurons arises after pubertal development. PLoS ONE 8 e58698. (https://doi.org/10.1371/journal.pone.0058698)

Cunningham ET, Miselis RR \& Sawchenko PE 1994 The relationship of efferent projections from the area postrema to vagal motor and brain stem catecholamine-containing cell groups: an axonal transport and immunohistochemical study in the rat. Neuroscience 58 635-648. (https://doi.org/10.1016/0306-4522(94)90087-6)

Ebisui O, Fukata J, Tominaga T, Murakami N, Kobayashi H, Segawa H, Muro S, Naito Y, Nakai Y \& Masui Y 1992 Roles of interleukin-1 alpha and -1 beta in endotoxin-induced suppression of plasma gonadotropin levels in rats. Endocrinology 130 3307-3313. (https:// doi.org/10.1210/endo.130.6.1597143)

Ericsson A, Kovacs KJ \& Sawchenko PE 1994 A functional anatomical analysis of central pathways subserving the effects of interleukin-1 on stress-related neuroendocrine neurons. Journal of Neuroscience $\mathbf{1 4}$ 897-913. (https://doi.org/10.1523/JNEUROSCI.14-02-00897.1994)

Franklin KBJ \& Paxinos G 2013 Paxinos and Franklin's the Mouse Brain in Stereotaxic Coordinates. Amsterdam, Netherlands: Academic Press.

Goodman RL \& Karsch FJ 1980 Pulsatile secretion of luteinizing hormone: differential suppression by ovarian steroids. Endocrinology 107 1286-1290. (https://doi.org/10.1210/endo-107-5-1286)

Goodman RL, Lehman MN, Smith JT, Coolen LM, De Oliveira CV, Jafarzadehshirazi MR, Pereira A, Iqbal J, Caraty A, Ciofi P, et al. 2007 Kisspeptin neurons in the arcuate nucleus of the ewe express both dynorphin A and neurokinin B. Endocrinology 148 5752-5760. (https://doi.org/10.1210/en.2007-0961)

Hansen MK, Taishi P, Chen Z \& Krueger JM 1998 Vagotomy blocks the induction of interleukin-1beta (IL-1beta) mRNA in the brain of rats in response to systemic IL-1beta. Journal of Neuroscience 18 2247-2253. (https://doi.org/10.1523/JNEUROSCI.18-06-02247.1998)

Harlow E \& Lane D 2006 Mounting samples in gelvatol or mowiol. CSH Protocols 2006 pdb.prot4461. (https://doi.org/10.1101/pdb.prot4461)

Ishizuka Y, Ishida Y, Kunitake T, Kato K, Hanamori T, Mitsuyama Y \& Kannan H 1997 Effects of area postrema lesion and abdominal vagotomy on interleukin-1 beta-induced norepinephrine release in the hypothalamic paraventricular nucleus region in the rat. Neuroscience Letters 223 57-60. (https://doi.org/10.1016/s03043940(97)13388-2)

Karsch FJ, Battaglia DF, Breen KM, Debus N \& Harris TG 2002 Mechanisms for ovarian cycle disruption by immune/ inflammatory stress. Stress 5 101-112. (https://doi. org/10.1080/10253890290027868)

Kinsey-Jones JS, Li XF, Knox AM, Wilkinson ES, Zhu XL, Chaudhary AA, Milligan SR, Lightman SL \& O'Byrne KT 2009 Down-regulation of hypothalamic kisspeptin and its receptor, Kiss1r, mRNA expression is associated with stress-induced suppression of luteinising hormone secretion in the female rat. Journal of Neuroendocrinology 21 20-29. (https://doi.org/10.1111/j.1365-2826.2008.01807.x)

Kreisman M, McCosh R, Tian K, Song C \& Breen K 2019 Estradiol enables chronic corticosterone to inhibit pulsatile LH secretion and suppress Kiss1 neuronal activation in female mice. Neuroendocrinology 110 501-516. (https://doi.org/10.1159/000502978)

Lee HY, Whiteside MB \& Herkenham M 1998 Area postrema removal abolishes stimulatory effects of intravenous interleukin-1beta on hypothalamic-pituitary-adrenal axis activity and c-fos mRNA in the hypothalamic paraventricular nucleus. Brain Research Bulletin $\mathbf{4 6}$ 495-503. (https://doi.org/10.1016/s0361-9230(98)00045-8)

Livak KJ \& Schmittgen TD 2001 Analysis of relative gene expression data using real-time quantitative PCR and the 2(-delta delta $\mathrm{C}(\mathrm{T})$ ) method. Methods 25 402-408. (https://doi.org/10.1006/meth.2001.1262)

Matsuwaki T, Eskilsson A, Kugelberg U, Jonsson JI \& Blomqvist A 2014 Interleukin-1beta induced activation of the hypothalamuspituitary-adrenal axis is dependent on interleukin-1 receptors on non-hematopoietic cells. Brain, Behavior, and Immunity 40 166-173. (https://doi.org/10.1016/j.bbi.2014.03.015)

McCosh RB, Kreisman MJ \& Breen KM 2018 Frequent tail-tip blood sampling in mice for the assessment of pulsatile luteinizing hormone secretion. Journal of Visualized Experiments 31 57894. (https://doi. org/10.3791/57894)

McCosh RB, Kreisman MJ, Tian K, Ho BS, Thackray VG \& Breen KM 2019 Insulin-induced hypoglycemia suppresses pulsatile LH secretion and arcuate kiss1 cell activation in female mice. Journal of Neuroendocrinology 31 e12813. (https://doi.org/10.1111/jne.12813)

McEntee CP, Finlay CM \& Lavelle EC 2019 Divergent roles for the IL-1 family in gastrointestinal homeostasis and inflammation. Frontiers in Immunology 10 1266. (https://doi.org/10.3389/fimmu.2019.01266)

MohanKumar SM \& MohanKumar PS 2002 Effects of interleukin-1 beta on the steroid-induced luteinizing hormone surge: role of norepinephrine in the medial preoptic area. Brain Research Bulletin 58 405-409. (https://doi.org/10.1016/s0361-9230(02)00809-2)

Moore AM, Coolen LM \& Lehman MN 2019 Kisspeptin/neurokinin B/ dynorphin (KNDy) cells as integrators of diverse internal and external cues: evidence from viral-based monosynaptic tract-tracing in mice. Scientific Reports 9 14768. (https://doi.org/10.1038/s41598-019-51201-0)

Rivest S, Torres G \& Rivier C 1992 Differential effects of central and peripheral injection of interleukin-1 beta on brain c-fos expression and neuroendocrine functions. Brain Research 587 13-23. (https://doi. org/10.1016/0006-8993(92)91424-d)

Rivier C \& Vale W 1989 In the rat, interleukin-1 alpha acts at the level of the brain and the gonads to interfere with gonadotropin and sex steroid secretion. Endocrinology 124 2105-2109. (https://doi. org/10.1210/endo-124-5-2105)

Sawchenko PE \& Swanson LW 1982 The organization of noradrenergic pathways from the brainstem to the paraventricular and supraoptic nuclei in the rat. Brain Research 257 275-325. (https://doi. org/10.1016/0165-0173(82)90010-8)

Schiltz JC \& Sawchenko PE 2007 Specificity and generality of the involvement of catecholaminergic afferents in hypothalamic responses to immune insults. Journal of Comparative Neurology $\mathbf{5 0 2}$ 455-467. (https://doi.org/10.1002/cne.21329)

Schindelin J, Arganda-Carreras I, Frise E, Kaynig V, Longair M, Pietzsch T, Preibisch S, Rueden C, Saalfeld S, Schmid B, et al. 2012 Fiji: an 
open-source platform for biological-image analysis. Nature Methods 9 676-682. (https://doi.org/10.1038/nmeth.2019)

Silva JF, Henriques PC, Campideli-Santana AC, Araujo-Lopes R, Aquino NSS, Hipolito LTM, Lopes-Aguiar C, Reis AM, Grattan DR \& Szawka RE 2020 Estradiol potentiates but is not essential for prolactininduced suppression of luteinizing hormone pulses in female rats. Endocrinology 161 bqaa022. (https://doi.org/10.1210/endocr/bqaa022)

Steyn FJ, Wan Y, Clarkson J, Veldhuis JD, Herbison AE \& Chen C 2013 Development of a methodology for and assessment of pulsatile luteinizing hormone secretion in juvenile and adult male mice. Endocrinology 154 4939-4945. (https://doi.org/10.1210/en.2013-1502)

Tonsfeldt KJ, Schoeller EL, Brusman LE, Cui LJ, Lee J \& Mellon PL 2019 The contribution of the circadian gene Bmal1 to female fertility and the generation of the preovulatory luteinizing hormone surge. Journal of the Endocrine Society 3 716-733. (https://doi.org/10.1210/js.2018-00228)
Turnbull AV \& Rivier CL 1999 Regulation of the hypothalamicpituitary-adrenal axis by cytokines: actions and mechanisms of action. Physiological Reviews 79 1-71. (https://doi.org/10.1152/ physrev.1999.79.1.1)

van der Kooy D \& Koda LY 1983 Organization of the projections of a circumventricular organ: the area postrema in the rat. Journal of Comparative Neurology 219 328-338. (https://doi.org/10.1002/ cne.902190307)

Yang JA, Song CI, Hughes JK, Kreisman MJ, Parra RA, Haisenleder DJ, Kauffman AS \& Breen KM 2017 Acute psychosocial stress inhibits LH pulsatility and Kiss1 neuronal activation in female mice. Endocrinology 158 3716-3723. (https://doi.org/10.1210/en.2017-00301)

Yeo SH, Kyle V, Blouet C, Jones S \& Colledge WH 2019 Mapping neuronal inputs to Kiss 1 neurons in the arcuate nucleus of the mouse. PLoS ONE 14 e0213927. (https://doi.org/10.1371/journal.pone.0213927)

Received in final form 19 May 2020

Accepted 28 May 2020

Accepted Manuscript published online 28 May 2020
(C) 2020 Society for Endocrinology Published by Bioscientifica Ltd.
Printed in Great Britain 